\title{
THE ERGONOMIC ASSESSMENT OF CYCLE RICKSHAW OPERATORS USING RAPID UPPER LIMB ASSESSMENT (RULA) TOOL AND RAPID ENTIRE BODY ASSESSMENT (REBA) TOOL
}

doi: $\quad 10.2478 /$ czoto-2019-0028

Date of submission of the article to the Editor: $03 / 11 / 2018$

Date of acceptance of the article by the Editor: 27/12/2018

Mahesh S. Gorde ${ }^{1}$-orcid id: 0000-0002-3300-9381

Atul B. Borade ${ }^{2}$-orcid id: 0000-0002-6349-6707

1 Jawaharlal Darda college of Engg. \& Technology, India

²Government Polytechnic college, India, atulborade@rediffmail.com

\begin{abstract}
In India, the population of about eight lacks people who are engaged in riding cycle rickshaw as an occupation. It is an unorganized sector of India. A cycle rickshaw is a modified form of bicycle which is the cheapest mode of transportation for carrying passengers, luggage and goods. Many tasks connected with this occupation are associated with strenuous body postures, and some body movements typical for this job which, when combined with a heavy load, result in frequent work-related musculoskeletal disorders (WMSDs).Working postures were analyzed by means of Rapid Upper Limb Assessment (RULA) tool and Rapid Entire Body Assessment (REBA) tool in order to determine the area of discomfort. The outcome of the research is beneficial for manufactures of cycle rickshaws and similar products well as users of such products, including cycle rickshaw operators. Some suggestions were given to have increase the comfort and safety level.
\end{abstract}

Keywords: Ergonomics, RULA, REBA, cycle rickshaw, WMSDs

\section{INTRODUCTION}

A number of studies has been carried out concerning various aspects of a cycle rickshaw, such as energy expenditure of cycle rickshaw operators in different parts of India (Pradhan et al. 2004, Pradhan et al. 2008). A number of anthropometric studies has been conducted in India on agricultural workers (Dhara et al. 2005, Kar et al. 2003, Yadav et al. 1997, Gite et al. 1989, Gupta, et al. 2003, in which anthropometric data of various parts of the body have been reported for general population in India(Manna et al. 2001, Chakrabarti et al. 1997, Chakrabarti 1996, Fernandez 1992). These studies were carried out in order to collect the data anthropometric data for 34 body measurements especially for Eastern India (Pradhan et al. 2010).

The present analysis was performed for two operating postures that were found to be potentially harmful. Postures typical for the job were analyzed by means of Rapid Upper Limb Assessment (RULA) tool and Rapid Entire Body Assessment (REBA) tool 
in order to assess the areas of discomfort. The outcome of the research is beneficial for manufactures of cycle rickshaws and similar products well as users of such products, including cycle rickshaw operators.

\subsection{CYCLE RICKSHAW}

A pedal-operated rickshaw is a modified bicycle- which is used extensively as a mode of transport for carrying passengers and luggage. Tricycle originates in Japan and dates back around 1868. At that time, such a manpower vehicle was called "Jinriksha". Tricycles, widely used in Asian countries, vary in style and may have different names such as Trishaw, Pedicab, Cyclo and Becaks. A cycle rickshaw is often perceived as an environment friendly and a less expensive mode of transportation. Since it is considered a traditional Indian traditional vehicle, it can be spotted in every part of India; in villages, small towns, metros, heritage sites etc. It is, however, an unorganized sector of transport in India. In metros, cycle rickshaws are used inside institutional areas, market places and, also, in narrow and crowded lanes where there is an accessibility problem for vehicles. A cycle rickshaw is available in various types depending on the their intended use i.e., for carrying passengers, luggage or merchandise.

\subsection{RAPID UPPER LIMB ASSESSMENT (RULA) TOOL AND RAPID ENTIRE BODY ASSESSMENT (REBA) TOOL}

Rapid Upper Limb Assessment (RULA) tool was proposed by McAtamney, L. \& Corlett, E.N. in 1993 (Lynn McAtamney et al. 1993) and by Hignett and Mc.Atamney in 2000 (Hignett, S. and McAtamney, L 2000) as a means of assessing a posture which poses a risk of work related musculoskeletal disorders (WRMSDs), and determining critical tasks in this occupation. For each task, it is supposed to assess posture factors by assigning a score to each area. The RULA and REBA tools use a systematic process to evaluate the whole body postural musculoskeletal disorders (MSD) and risks associated with tasks typical for this job. A one page worksheet is used to evaluate the required or selected body posture, forceful exertions, type of movement or action and repetition. The RULA and REBA were designed for an easy use without a need for an advanced degree in ergonomics or expensive equipment. Using the RULA and REBA worksheet, an evaluator can attribute a score to each of the following body regions: wrists, forearms, elbows, shoulders, neck, trunk, back, legs and knees. After the data for each region is collected and scored, Tables 1 and Table 2 are used to compile the risk factor variables, generating a single score that represents the level of work-related musculoskeletal disorders (WMSDs) risk.

Table 1

For finalising conclusion on RELA analysis

\begin{tabular}{|c|c|c|}
\hline Analysis Score & WMSDs risk level & Action Required \\
\hline $1-2$ & lgnorable & No action required \\
\hline $3-4$ & Low risk & Change may be needed \\
\hline $5-6$ & Medium risk & Further investigation, Change soon \\
\hline $6+$ & Very high risk & Immediate change to be implemented \\
\hline
\end{tabular}


Table 2

For finalising conclusion on RULA analysis

\begin{tabular}{|c|c|c|}
\hline Analysis Score & WMSDs risk level & Action Required \\
\hline 1 & Ignorable risk & No action required \\
\hline $2-3$ & Low risk & Change may be needed \\
\hline $4-7$ & Medium risk & Further investigation, change soon \\
\hline $8-10$ & High risk & Investigate and implement change \\
\hline $11+$ & Very high risk & Immediate change to be implemented \\
\hline
\end{tabular}

\subsection{WORK-RELETED MUSCULOSKELETAL DISORDERS}

Work-related musculoskeletal disorders is a term given to a group of disorders involving the muscles, joints, nerves and vascular compartment of the body, where certain jobs or work-related factors are associated with an increased risk of developing such disorders. Musculoskeletal disorders (MSDs) are the most common type of work-related health problem in India. Disorders of neck, chest, thigh, back, foot are common problems among the general population as well as cycle rickshaw riders in India.

\section{RESEARCH OBJECTIVES}

This paper deals with the ergonomic assessment of cycle rickshaw operators. The research was done in India to identify high risk working postures while riding a cycle rickshaw, and to suggest improvement in which can prevent work-related musculoskeletal disorders. Rapid Upper Limb Assessment (RULA) and Rapid Entire Body Assessment (REBA) were carried out to assess the risk zone of a cycle rickshaw rider. The main objective of the research work is to determine the risk zone of cycle rickshaw riding.

\section{WORKING POSTURE ANALYSIS USING RULA AND REBA TOOL}

Two main body positions on Cycle rickshaws riding were examined in the research:

1. Pedalling while standing position.

2. Pedalling while sitting position.

Those who were potentially at ergonomic risk of entire body injuries; were investigated in an analytical-descriptive study. Participants of the research were male cycle rickshaw operators between the age of 23 and 55, with mean age of 42.6 (SD = 36.30 years) being the average age of a participant. All of them underwent a preliminary interview, as information about their job characterization had to be obtained. Rapid Upper Limb Assessment (RULA) tool and Rapid Entire Body Assessment (REBA) tool were applied for assessing a rider entire body musculoskeletal risk factors associated with various tasks.

\subsection{PEDALLING IN A STANDING POSITION}

Two pedal cranks are mounted on a crank shaft to make pedalling a cycle rickshaw possible. A circular pedalling motion is achieved with an oscillatory movement of powerful thigh muscles of a rider. To accelerate a cycle rickshaw from a rest condition or very low speed required more torque is required, so a cycle rickshaw rider adopts a stand-up position, as shown in Figure 1, in order to exert higher force on pedals. 


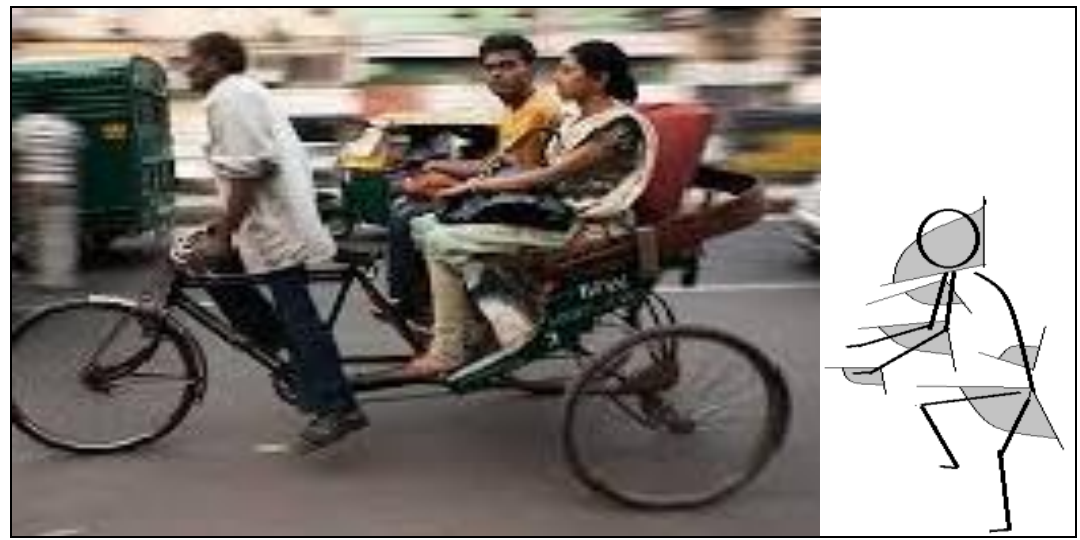

Fig. 1. A cycle rickshaw operator pedalling in a standing position

The Rapid Upper Limb Assessment (RULA) analysis of a cycle rickshaw operator in a standing position are shown in Table 3, where the arm and wrist analysis as well as neck, trunk and leg analysis is carried out according to the guidelines (Lynn McAtamney et al, 1993). The Rapid Entire Body Assessment (REBA) analysis of a cycle rickshaw operator in a standing position is also carried out as shown in Table 4, where trunk, neck and legs' analysis and upper arms (shoulders), lower arms (elbows) and wrists' analysis are carried out according to the guidelines (Hignett, S. and McAtamney, L., 2000).

Table 3

RULA analysis of a cycle rickshaw operator pedalling in a standing position

\begin{tabular}{|c|c|c|}
\hline RULA & Working position & Score \\
\hline \multirow[t]{4}{*}{ Arm \& wrist analysis } & $\begin{array}{l}\text { Upper arm position }\left(20^{0}-45^{0}\right) \\
\text { Lower arm position }\left(60^{\circ}-100^{\circ}\right) \\
\text { Wrist position }\left( \pm 15^{0}\right) \\
\text { Wrist twist }\end{array}$ & $\begin{array}{l}2 \\
1 \\
3 \\
2\end{array}$ \\
\hline & Posture Score A & 4 \\
\hline & $\begin{array}{l}\text { Muscle use score } \quad \text { (action repeated) } \\
\text { Force/load score (more than } 22 \text { lbs.) }\end{array}$ & $\begin{array}{l}1 \\
2\end{array}$ \\
\hline & Wrist and arm score & 7 \\
\hline \multirow[t]{4}{*}{$\begin{array}{l}\text { Neck, trunk and leg } \\
\text { analysis }\end{array}$} & $\begin{array}{l}\text { Neck position }\left(20^{\circ}\right) \\
\text { Trunk position }\left(20^{\circ}-60^{\circ}\right) \\
\text { Legs (not supported) }\end{array}$ & $\begin{array}{l}3 \\
3 \\
2\end{array}$ \\
\hline & Posture score B & 5 \\
\hline & $\begin{array}{l}\text { Muscle use score (action repeated) } \\
\text { Force/load score (more than } 22 \text { lbs.) }\end{array}$ & $\begin{array}{l}1 \\
2\end{array}$ \\
\hline & Neck, trunk and leg score & 8 \\
\hline \multicolumn{2}{|l|}{ Final score } & 7 \\
\hline
\end{tabular}

Table 4

REBA analysis of a cycle rickshaw operator pedalling in a standing position

\begin{tabular}{|l|l|c|}
\hline REBA & Working position & Score \\
\hline \multirow{3}{*}{ Trunk, neck and } & Trunk $\left(20^{\circ}-60^{\circ}\right)$ & 3 \\
& Neck (Extension $>20^{\circ}$ and twist) & 3 \\
& Legs unilateral load bearing & 2 \\
\cline { 2 - 3 } & Posture score A & $\mathbf{5}$ \\
\cline { 2 - 3 } & Load/ force $(>10 \mathrm{~kg}$ ) & 2 \\
& Activity (Rapid changes in posture) & $\mathbf{8}$ \\
\cline { 2 - 3 } & Trunk, neck and legs score & \\
\hline
\end{tabular}




\begin{tabular}{|c|c|c|}
\hline \multirow{4}{*}{$\begin{array}{l}\text { Upper arms } \\
\text { (Shoulders), lower } \\
\text { arms (elbows) and } \\
\text { wrists }\end{array}$} & $\begin{array}{l}\left.\text { Upper arms (Flexion } 45^{\circ}-90^{\circ}\right) \\
\text { Lower arms (Flexion } 60^{\circ}-100^{\circ} \text { ) } \\
\text { Wrists (Flexion> } 15^{0} \text { ) }\end{array}$ & $\begin{array}{l}3 \\
1 \\
2\end{array}$ \\
\hline & Posture score B & 4 \\
\hline & Coupling (Poor) & 2 \\
\hline & Upper arms, lower arms and wrists score & 6 \\
\hline \multicolumn{2}{|l|}{ Final score } & 10 \\
\hline
\end{tabular}

\subsection{PEDALling IN A SITTING POSITION}

To accelerate a cycle rickshaw from a rest position or a very low speed more torque is required, so a cycle rickshaw rider adopts a stand-up position. After getting a standard uniform speed or desired speed, a cycle rickshaw operator adopts another position i.e. a sitting position, as shown in Figure 2, which is analysed by means of RULA and REBA.

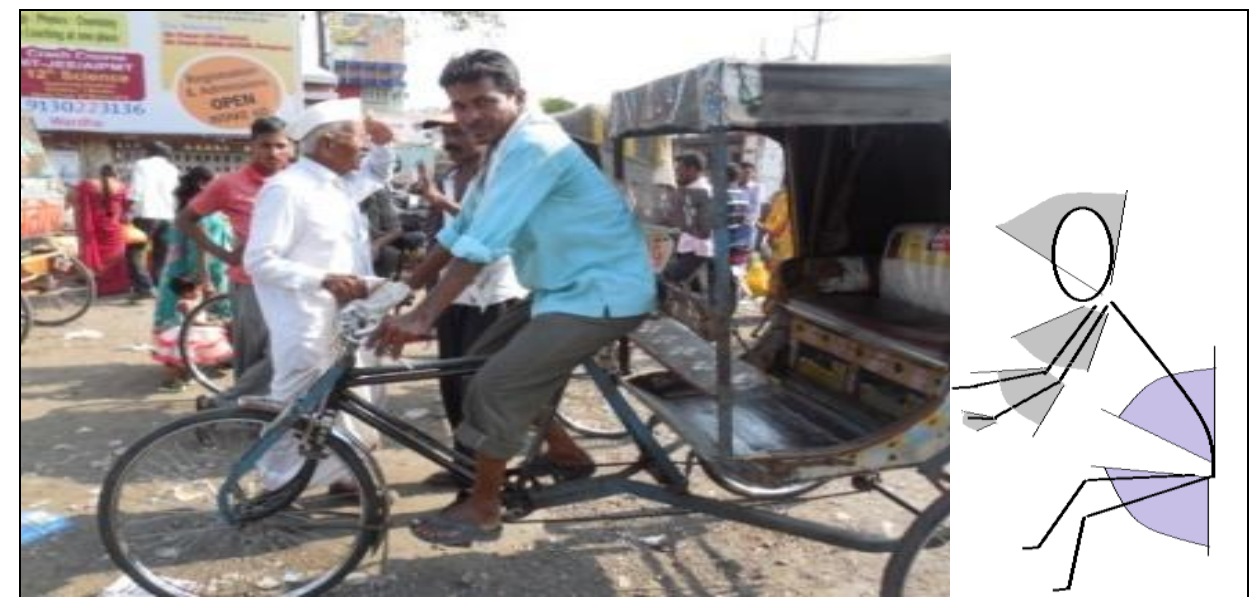

Fig. 2. An Indian cycle rickshaw operator pedaling in a sitting position

The Rapid Upper Limb Assessment (RULA) analysis of a cycle rickshaw operator adopting a sitting position is shown in Table 5, where the arm and wrist analysis as well as neck, trunk and leg analysis is carried out according to the guidelines (Lynn McAtamney et al, 1993). The Rapid Entire Body Assessment (REBA) analysis of a cycle rickshaw operator in a standing position is also carried out as shown is Table 6 , where trunk, neck and legs analysis and upper arms (shoulders), lower arms (elbows) and wrists analysis are carried out in accordance with the guidelines (Hignett, S. and McAtamney, L., 2000).

Table 5

RULA analysis of a cycle rickshaw operator pedaling in a sitting position

\begin{tabular}{|l|l|c|}
\hline RULA & \multicolumn{1}{|c|}{ Working position } & Score \\
\hline \multirow{4}{*}{ Arm \& wrist analysis } & Working position & Score \\
\cline { 2 - 3 } & Upper arm position $\left(45^{0}-90^{\circ}\right)$ & 3 \\
& Lower arm position $\left(60^{\circ}-100^{\circ}\right)$ & 1 \\
& Wrist position $\left( \pm 15^{0}\right)$ & 3 \\
& Wrist twist & 2 \\
\cline { 2 - 3 } & Posture score A & $\mathbf{4}$ \\
\cline { 2 - 3 } & Muscle use score & 1 \\
\hline Neck, trunk and leg & Force/load score (More than 22 lbs.) & 2 \\
\hline \multirow{2}{*}{ analysis } & Wrist and arm score & 2 \\
\cline { 2 - 3 } & Neck position (10-20 & 2 \\
\hline
\end{tabular}




\begin{tabular}{|l|l|l|}
\hline & Legs (Not supported) & 2 \\
\cline { 2 - 3 } & Posture score B & $\mathbf{3}$ \\
\cline { 2 - 3 } & Muscle use score (Action repeated) & 1 \\
& Force/Load score (More than 22 lbs.) & 2 \\
\hline Final score & $\mathbf{7}$ \\
\hline
\end{tabular}

Table 6

REBA analysis of a cycle rickshaw operator pedaling in a sitting position

\begin{tabular}{|c|c|c|}
\hline REBA & Working position & Score \\
\hline \multirow[t]{4}{*}{$\begin{array}{l}\text { Trunk, neck and legs } \\
\text { analysis }\end{array}$} & $\begin{array}{l}\text { Trunk }\left(20^{\circ}-60^{\circ}\right) \\
\text { Neck }\left(0^{\circ}-20^{\circ} \text { and twist }\right) \\
\text { Legs unilateral load bearing and knees flexion > } \\
60^{\circ}\end{array}$ & $\begin{array}{l}3 \\
2 \\
4\end{array}$ \\
\hline & Posture score A & 7 \\
\hline & $\begin{array}{l}\text { Load/ force (>10 kg) } \\
\text { Activity (Rapid changes in posture) }\end{array}$ & $\begin{array}{l}2 \\
1\end{array}$ \\
\hline & Trunk, neck and legs score & 10 \\
\hline \multirow[t]{4}{*}{$\begin{array}{l}\text { Upper Arms } \\
\text { (shoulders), lower arms } \\
\text { (elbows) and wrists }\end{array}$} & $\begin{array}{l}\left.\text { Upper arms (Flexion20 }-45^{\circ}\right) \\
\text { Lower arms (Flexion60 } 60^{\circ}-100^{\circ} \text { ) } \\
\text { Wrists (Flexion> } 15^{\circ} \text { ) }\end{array}$ & $\begin{array}{l}2 \\
1 \\
2\end{array}$ \\
\hline & Posture score B & 2 \\
\hline & Coupling (Poor) & 2 \\
\hline & Upper arms, lower arms and wrists score & 4 \\
\hline \multicolumn{2}{|l|}{ Final score } & 11 \\
\hline
\end{tabular}

\section{RESULT ANALYSIS}

After the examination of the two operating positions of a cycle rickshaw operator, it was discovered that the score of RULA analysis of a cycle rickshaw operator pedalling in a standing position is 7 (Table 3 ) and the score of REBA analysis of a cycle rickshaw operator pedalling while standing position is 10 (Table 4). In case of the second position that is pedalling while sitting condition the RULA score is 7 (Table 5) and REBA score is 11 (Table 6). These scores of RULA and REBA of operating position are compared with the value of Table 1 and Table 2 respectively.

The value of RULA i.e. is 7 and REBA i.e. is 10 scores for a standing position and the value of RULA i.e. is 7 and REBA i.e. is 11 scores for a sitting position, which indicates that the considered working posture under consideration is poses a very high risk. Therefore, an immediate change needs to be implemented in order to reduce risk factors (Table 1 and 2]. As the RULA and REBA score of both is in the high risk zone, the working posture needs an immediate investigation and changes are necessary in the design of a cycle rickshaw. Training for proper sitting as well as standing posture is required so as to reduce the work-related musculoskeletal disorders (WMSDs) and improve the health condition of cycle rickshaw operators in India.

\section{CONCLUSION}

As the anthropometric characteristics of cycle rickshaw operators were different from those of the Indian population, a cycle rickshaw should be designed in accordance with local anthropometric data. Otherwise, the height of a rider's seat from a pedal (crotch height) and the distance between a rider's seat and a handle (Forward grip reach) should a have structure with variable adjustments corresponding to $\ddagger$ an individual rickshaw operator. Owing to this research, one is able to identify the most hazardous operating posture that needs an immediate investigation and improvement. 
Knowledge about risk factors in order to prevent disability is an essential issue for cycle rickshaw operators.

\section{ACKNOWLEDGEMENTS}

The authors are grateful to Dr. Chandan K Pradhan, Regional Occupational Health Centre (Eastern),Indian Council of Medical Research, India who assisted in completing the research and to cycle rickshaw pullers who voluntarily participated in the study.

\section{REFERENCES}

Pradhan, CK, Thakur, S, Mukherjee, AK, and Roychowdhury, A., 2004. Physiological assessment of cycle rickshaw pullers. Indian J Physiology and Allied Sciences, 58: 113-118.

Pradhan, CK, Thakur, S, Mukherjee, A and Roychowdhury A., 2008. Energy expenditure of cycle rickshaw pullers in different places in India. Ergonomics, 51: 1407-1417.

Dhara, PC, Kar, SK, Manna, I., Ghosh, S, Sau, S and Banerjee, S., 2005. Body dimension and body composition of agricultural workers of Eastern India. Indian Journal of Physiology and Allied Sciences, 59: 111-123.

Kar, SK, Ghosh, S, Manna, I, Banerjee, S and Dhara P., 2003. An investigation of hand anthropometry of agricultural workers. J. Human Ecology, 14: 57-62.

Yadav, R, Tiwari, VK, and Prasad, N., 1997. Anthropometric data of Indian farm worker - a module analysis. Applied Ergonomics, 21: 69-71.

Gite, LP, and Yadav, BG., 1989. Anthropometric survey for agricultural machinery design. Applied Ergonomics, 20: 191-196.

Gupta, PK, Sharma, AP and Gupta, ML., 1983. Anthropometric survey of Indian farm workers. Agricultural Mechanisation in Asia, 14: 27-30.

Manna, I, Pradhan, D, Ghosh, S, Kar, SK and Dhara P., 2001. A comparative study foot dimension between adult male and female and evaluation of foot hazards due to using footwear. J Physiological Anthropology and Applied Human Science, 20: 241-246.

Chakrabarti, D. 1997. Indian Anthropometric Dimensions for Ergonomic Design Practice. National Institute of Design, Ahmedabad.

Chakrabarti, D, and Nag, PK. 1996. Human concept in workspace design. Ergonomics and work Design, ed. By Nag PK, New Age International Publishers, New Delhi : Ch 8, 129-157.

Fernandez, JE, and Uppugonduri, KG 1992. Anthropometry of South Indian industrial workmen. Ergonomics, 35: 1393- 1398.

Pradhan C.K., Thakur S., Mukherjee A.K.,2010. Anthropometric characteristics of Indian cycle rickshaw pullers, Journal of Human Ergology 39 (2).

Lynn McAtamney et al., 1993. "RULA: a survey method for the investigation of worldrelated upper limb Disorders," Applied Ergonomics.

Hignett, S. and McAtamney, L., 2000. "REBA: A Survey Method for the Investigation of Work-Related Upper Limb Disorders," Applied Ergonomics. 